BULLETIN Bulletin hispanique

HISPANIQUE Université Michel de Montaigne Bordeaux

116-1 | 2014

Varia

\title{
L. de Vega Carpio, Comedias. Parte XI
}

Gredos, Madrid, 2012

Adrián J. Sáez

\section{OpenEdition}

1 Journals

Edición electrónica

URL: http://journals.openedition.org/bulletinhispanique/3330

DOI: 10.4000/bulletinhispanique.3330

ISSN: $1775-3821$

Editor

Presses universitaires de Bordeaux

Edición impresa

Fecha de publicación: 1 junio 2014

Paginación: 457-464

ISBN: 978-2-86781-931-5

ISSN: 0007-4640

Referencia electrónica

Adrián J. Sáez, «L. de Vega Carpio, Comedias. Parte XI », Bulletin hispanique [En línea], 116-1 | 2014

Publicado el 01 junio 2014, consultado el 23 septiembre 2020. URL : http://journals.openedition.org/

bulletinhispanique/3330; DOI : https://doi.org/10.4000/bulletinhispanique.3330

Este documento fue generado automáticamente el 23 septiembre 2020

Tous droits réservés 


\section{L. de Vega Carpio, Comedias. Parte XI}

Gredos, Madrid, 2012

Adrián J. Sáez

\section{REFERENCIA}

L. de Vega Carpio, Comedias. Parte XI, coord. L. Fernández y G. Pontón, Madrid, Gredos, 2012, 2 vols. (Biblioteca Lope de Vega.) - ISBN 978-84-89790-00-1.

1 La fortuna sonríe la empresa editorial de Prolope, grupo embarcado en la gran hazaña de sacar «en limpio»-como decía Cela sobre su Pascual Duarte- las muchas comedias de Lope de Vega. Todavía queda un largo camino por delante hasta la Parte XXX, pero el rumbo sigue el soplo de los vientos. A partir de ahora, además, cambian de casa y salen en la editorial Gredos, un lugar de honor para quien bien lo merece: uno de los mayores dramaturgos de todos los tiempos y un proyecto tan ambicioso como fructífero.

La coordinación de este onceno volumen ha corrido a cargo de Laura Fernández y Gonzalo Pontón, quienes para empezar trazan la historia editorial de la Parte XI, la tercera cuya publicación gestiona directamente Lope. Estas páginas iniciales resultan cruciales para conocer la frenética actividad del dramaturgo en 1617 y 1618 en sus afanes editoriales. Fernández y Pontón revelan las claves de un trabajo que el poeta realizaba al alimón con una camarilla de colaboradores, entre los que se cuenta el duque de Sessa que atesoraba los originales de su protegido: «se trata [...] sobre todo, de una apuesta editorial, en la que el ingenio iba en parte a remolque de las necesidades o de las propuestas de los libreros que costearon la iniciativa» (p. 3). Según se desprende de este y otros casos parejos, Lope supo aprovechar las dinámicas del mercado editorial en su favor mediante varias medidas y sus consecuentes triunfos: control de la calidad de los textos, victoria frente a la competencia, réditos económicos, etc. O lo que es lo mismo: «una plataforma periódica desde la que afirmar su personalidad literaria» (p. 4). Las razones que movieron a Lope quedan claras en su comentario: no suspira por el beneficio económico sino que más bien se mueve al ritmo que marcaban «cuestiones relativas al control de la[s] obras y a la circulación regulada de estas, para que no 
fuesen en menoscabo de su "opinión"» (p. 5), terreno en que no falta alguna pica en sus disputas literarias, en sintonía con la reimpresión de El peregrino en su patria y la salida de la Expostulatio Spongiae. Abreviando, esta primera introducción explica perfectamente el significado de los preliminares del tomo, de los que se puede espigar el tipo de expectativas de lectura que Lope apunta en su dedicatoria (textos adecuados para los cortesanos) y en el prólogo alegórico (nueva oportunidad de conocer las comedias).

3 Mención -y elogio- aparte merece el examen de los criterios de «orden y concierto» de la docena de comedias de la parte (pp. 12-17): asunto que despierta desde no ha mucho la curiosidad de la crítica, estas páginas contribuyen a avanzar por este camino. Primeramente, Fernández y Pontón aconsejan prudencia, porque ni todo es «puro capricho de principio a fin» ni siempre respiran «unidad y coherencia»; no en vano se trataba de «una miscelánea, la reunión en un nuevo contexto de elementos de procedencia y condición diversas» (p. 13) que -añado- no procedía de un cajón que Lope tuviese constantemente al alcance de la mano, de modo que las prisas pudieron tener que ver en la confección de las partes. Con todo y ello, la comedia de amor brilla con fuerza en el repertorio junto a las tensiones de esta pasión con el honor y la amistad, sin que parezca concurrir ningún otro criterio de corte cronológico o genérico. El orden, a su vez, parece proceder del cruce del criterio de Lope (ya esbozado en su lista peregrina) y de sus editores, una frontera siempre de difícil deslinde.

4 Sigue la descripción de los testimonios, entre los que subrayaré únicamente la princeps (Madrid, Viuda de Alonso Martín, 1618) y su reedición (Barcelona, Sebastián de Cormellas, 1618), que dejan vía franca al análisis del panorama textual, que ya en su primera publicación se aprecia muy pulcro y cuidado, con algunas correcciones en prensa a la cabeza. Este estado de cosas hace que, a diferencia de otros casos, la Parte XI valga por lo general como texto base, siendo los otros testigos una ayuda fundamental para labores de corrección y reparación.

5 Cada una de las comedias sigue el formato habitual del proyecto, repetido en la coda del prefacio general: prólogo con criterios más o menos uniformes (estudio de acción, género, fuentes y otros aspectos parejos, apartado ecdótico, resumen del argumento y sinopsis de la versificación). El aparato de variantes se encuentra al pie del texto y, bajo este, las notas aclaratorias; cada comedia se despide con un apéndice de variantes lingüísticas y una nota onomástica. Advierto de entrada que cada comedia ofrece dificultades desiguales tanto en la cara literaria como en la cruz textual, por lo que demandan competencias diversas a cada ocasión. De ser necesario, por tanto, me limitaré a sugerir algunas apostillas mínimas.

6 Tras los preliminares (aprobación de Gutierre de Cetina, suma del privilegio, lista de las comedias, tasa, fe de erratas, dedicatoria del dramaturgo a don Bernabé de Vivanco y Velasco, «Prólogo del Teatro a los lectores», poema encomiástico de Tamayo de Vargas a su amigo Lope y aprobación de la reimpresión barcelonsa), comienzan a desfilar las comedias. No es baladí que la parte se abra con El perro del hortelano (ed. Paola Laskaris), una de las comedias más aplaudidas del corpus lopesco, con los amores de la condesa Diana y el secretario Teodoro. El prólogo atiende al género un tanto híbrido, a caballo entre la palatina y la capa y espada, los vínculos con El vergonzoso en palacio de Tirso, la influencia italiana y la solución del enredo, entre otros puntos. Y, aunque «cada maestrillo tiene su librillo», falta un manojo de notas más: «gavilán» (v. 53, 'veloz'), «parentesco» (v.318, aquí 'familiaridad', pero no 'relación familiar'), algunas voces 
propias de la esgrima («Tiras, pero no reparas», v. 346 y lo que sigue) y precisar que «impírico» (v. 447) no es un «vulgarismo» sino una asimilación natural en la época.

Otra pieza maestra es El acero de Madrid (ed. Luis Gómez Canseco), que ya contaba con la benemérita edición de S. Arata, ejemplar en muy diversos sentidos. Pues bien, con este difícil parangón al frente, el trabajo de Gómez Canseco logra aportar mucho y bueno. En la introducción saca fruto al amplio semillero de esta "delicia literaria y escénica» (p. 279): la ambientación madrileña, el estatuto genérico, la dinámica de personajes y de la simulación, los juegos de lenguaje, etc. Acto seguido viene la reconstrucción de la transmisión textual y un trazado del éxito de la comedia en refundiciones y traducciones. La fijación del texto se sustenta -según confiesa el propio crítico- en la tradición editorial previa, a la que añade decisiones muy acertadas como el respeto de la forma «colesio» (v. 2691, que no es preciso corregir en «colegio»). Sencillamente modélica es la anotación, pues aclara todos los aspectos precisos (léxicos, literarios, movimientos escénicos, etc.) junto a su sentido simbólico y su función en la dinámica de la comedia (véase sólo la nota sobre la aurora, v. 9), además con una muy estimable elegancia expositiva que regala algunos guiños chistosos que alegran la lectura.

Los ramilletes de Madrid (ed. Elizabeth Wright) es la tercera comedia que sale al encuentro. En ella se imbrica una relación dramática de las dobles bodas hispanofrancesas de 1615 en los amores desarrollados en la corte. Esta crónica en verso de un suceso de la casa real recibe notables comentarios en el prólogo, donde se apunta que la desgracia del duque de Lerma pudo haber colaborado en el eclipse de esta comedia (p. 477). El texto presenta algunos pequeños yerros: se hace necesario restaurar algunas lecturas o errores («aprisa» y no «a prisa», v. 175; «encinta» y no «en cinta», v. 779; «acaso» y no «a caso», v. 1831), y subsanar un par de erratas («Tu llevarás» debe ser «Tú llevarás», v. 601; «ansí» por «ansi», v. 831). Sin cambiar de tercio, a Fabio le corresponden los vv. 57-58 (tal como está el locutor se le atribuye solo el último, si bien en nota se entiende el pasaje, pero de nuevo con error en la indicación de versos) y el uso de las comillas sería adecuado en la cita vv. 700-704, pues reproduce palabras del gracioso. También creo oportuno añadir unas cuantas aclaraciones más dentro del aparato de notas, porque a veces se aclara el pasaje en cuestión pero no ciertas voces: «espetera» (v. 89, «tabla de garfios donde se cuelgas las carnes [...] y otras cosas de cocina», Aut., y metafóricamente aquí 'lado'), «maro» (v. 277, planta no anotada del catálogo botánico), «menudo» (v. 761), el sustrato virgiliano de vv. 495-496 («[...] como el áspid, aquí / entre flores escondida»), el juego entre «Marcelo» y «martelo» (nombre propio y «[1]a unión y correspondencia cariñosa entre dos personas», Aut., que no ha de ir con mayúscula, v. 888), "pitipié» (v. 1151, «Línea dividida en alguna cantidad de partes iguales, que representan pies, varas, leguas u otra cualquier medida, y sirve para delinear con proporción en el papel la planta de cualquier terreno o edificio», Aut., y más detalles en el DYCTER), «miraba / [...] piramidalmente» (vv. 1299-1300, referencia a la «pirámide óptica», definida como una pirámide comprehendida de los rayos ópticos principales, que tiene por base al objeto y por cúspide al centro de cualquier de los ojos», Aut.), «randas» (v. 1679, 'adorno de encaje para ropas y vestidos', Aut.), «virotes» (v. 2001, «[e]specie de saeta guarnecida con un casquillo», Aut.), «copete y clin» (v. 2778, «pedazo de crin o mechón que a los caballos les cae sobre la frente de entre las orejas», Aut.; y 'los cabellos de la cerviz o el cuello del caballo', aquí con lateralización). En otro pasaje se percibe un eco ovidiano: «[...] es antigua opinión / que no cura amor con hierbas» (vv. 300-301), que puede remitir a diversos pasajes del Ars amandi («Viderit Haemoniae siquis mala pabula terrae / et mágicas artes posse iuvare putat. / Ista 
veneficii vetus est via», 249-251, por ejemplo, que cito según «The Art of Love» and Other Poems, ed. J. H. Mozley, Cambridge, Harvard University, 1985). Por fin, el nombre del gracioso « Moscatel » vale igualmente «borracho » (v. 849) en un caso y «mentecato » (v. 1735) en otro, como se puede apreciar gracias al trabajo de C. E. Aníbal, « Moscatel », Hispania, II, 1934, pp. 3-18.

9 Comedia del ciclo de Hungría es Obras son amores (ed. Carlos Mota), de trama principalmente amorosa. Se aclara la libertad de que hace gala Lope en la pintura del ambiente magiar, pero se podría haber explotado este vínculo en las sugerentes líneas sobre la intertextualidad, ya que las trazas de esta comedia no solo remiten a El lacayo fingido o ¡Si no vieran las mujeres!, sino también a las piezas húngaras (de El príncipe melancólico a La corona de Hungría) con las que se puede establecer una jugosa comparación. Entre estos réditos pienso, por ejemplo, en la cuestión genérica, que no se menciona en la introducción: Obras son amores es una comedia palatina cómica (de acuerdo con los trabajos de Zugasti) frente a El cuerdo loco, que pertenece al ámbito serio. La dinámica de la acción, la primacía del amor sobre el poder o el final ya lo revelan, pero el careo con otras calas de la misma serie (de la que, por cierto, todavía queda bastante por decir) podría resultar del mayor interés. Buenas enmiendas se hacen en vv. 57 («le suele»] «la suele») y 590 («espurga»] «es purga») para mejorar el sentido. Por este camino, creo que el ducado de «Arles» (v. 1065) debería de ser «Arlés», forma castellana que asimismo mejora el ritmo del verso, y sobra un punto en v. 1654 que rompe la frase.

10 La comedia urbana Servir a señor discreto (ed. José Enrique Laplana) entronca, historia de amor mediante, con el discurso sobre el perfecto secretario y un ejercicio de encomio genealógico. Estos y otros aspectos se aclaran bien en el prefacio, poniendo el acento en la personificación de la discreción en el conde de Palma, al margen de la reelaboración de sucesos históricos. La vida editorial de la pieza, con sus escasos problemas ecdóticos, deja paso a un texto bien fijado y anotado, labor en la que destacan dos enmiendas muy juiciosas («suelo», v. 342 y «el favor»] «Leonor», v. 1964, que restaura ope ingenii el sentido). Unas pocas notas que tal vez se echen de menos: "plieto» (vv. 126 y 127, que parece errata por «pleito»), «rostro de chacota» (v. 407, 'cara de risa y chanzas', Cov., como se explica en el v. siguiente), el simbolismo de la imagen de la muerte del cisne (v. 1147), una mínima aclaración sobre los dos personajes de La Celestina que se mencionan (vv. 1341-1342, aunque son cristalinas) y «rizo» (v. 1417, «[t]erciopelo rizo, que no está cortado, quasi rígido, porque está áspero al toque», Cov.).

11 Se pone fin al primer tomo con El príncipe perfeto (ed. Judith Farré Vidal), comedia de asunto histórico centrada en algunos episodios del rey João II de Portugal. Introducción y anotación dialogan con solvencia con la Crónica de García de Resende y examinan la reelaboración poética con la que Lope configura un espejo de gobernantes directamente destinado a Felipe III, amén de regalar unas jugosas notas sobre la intertextualidad que mantiene con la continuación de la comedia (publicada en la Parte XVIII) y El duque de Viseo. El panorama textual posee gran interés por dividirse en varios impresos y manuscritos, entre los que destaca uno que formaba parte del repertorio de la compañía de Alonso Riquelme, con memoriones de por medio. La adopción de la princeps como base es juiciosa, pero además recoge en nota algunas variantes lingüísticas porque aportan información sobre este cauce de transmisión (ver p. 932). Las notas, precisas, podrían acompañarse de otras tres: «la blanca» (v. 102, ver v. 121, 'arma blanca, con corte y punta' en oposición a la negra, que tiene un botón en la 
punta), «codicilio» (v. 377, «el escrito en que uno declara su última voluntad, aunque no requiera tanta solenidad como el testamento», Cov.) y «carrasco» (v. 737, se explica que es «flor con espinas de carrasca», pero resta decir que esta es una «[e]specie de encina pequeña», Cov.).

El segundo volumen de la parte principia con El amigo hasta la muerte (ed. Josefa Badía Herrera), comedia urbana con toques moriscos y una ligera ambientación histórica. La introducción subraya una posible aspiración a obtener el patrocinio del duque de Medina Sidonia y la valoración positiva de las actividades mercantiles en Sevilla. El estudio textual prueba la importancia del cotejo de ejemplares de la edición príncipe para subsanar errores y examina una refundición manuscrita custodiada en la BNE. Ya en el texto, la corrección del v. 3225 es muy sensata («hongos»] «órganos») y se podría ofrecer otra puntuación de la respuesta de Federico a la pregunta "¿qué quéreis de mí?» (v. 18) de Julia: no tanto «Veros hermosa» (v. 19) como se propone, pues vale «(quiero) veros bella», sino «Veros, hermosa» (v. 19), esto es, «quiero veros, dama hermosa», algo que solo puede alcanzar si se descubre, ya que está tapada con un manto. Una serie de términos se podrían explicar en las notas: «arracadas» (v. 74, «pendientes en forma de arillos», Cov.), «priscos» (v. 269, «especie de durazno», Cov., que se tendría que arrojar en el contexto jocoso que explica Guzmán), «cifra» (v. 379, «escritura enigmática, en clave», Cov.), «albéitar» (v. 918, «quien cura las enfermedades a las bestias», Cov., referencia cómica en boca del gracioso), «manillas» (v. 957, «ajorcas que las mujeres traen en los brazos», Cov.), «guindaré» (v. 1555, «elevaré, subiré», Aut.) y «quínolas» (v. 2512, un tipo de juego de cartas que comenta J.-P. Étienvre). Otro pasaje merece revisarse: en «Resolución de mujer,/tudesco sin paso atrás»

(vv. 211-212), «tudesco» se explica como «sinónimo de "capote"» porque su sentido de «ceño fruncido» que da Autoridades hace que «en el verso tiene sentido de "inflexible"». Pues bien, en realidad creo que se refiere a la imagen coetánea de los alemanes (tudescos), que entre otros rasgos eran tenidos por buenos soldados, especialmente por «su firmeza en mantener las posiciones una vez tomadas», como señala M. Herrero García (Ideas de los españoles del siglo XVII, 2. ${ }^{a}$ ed., Madrid, Gredos, 1966, p. 571), quien añade la predilección de Lope por acudir a «este tópico de la opinión acerca de los alemanes para expresar comparativamente firmezas y resoluciones inquebrantables en materia de amor» (p. 571), con diversos pasajes de La Dorotea y una serie de comedias. Más adelante «tudesco» (v. 899) tampoco significa «malcarado» sino más bien «valiente o temerario», esto es: «¿Por qué te haces el valiente?», le espeta Guzmán a Bernardo. Por último, en la introducción o la anotación se tendría que haber comentado que la escena del baño de Arlaja que interrumpe Bernardo (vv. 1367-1450) se modela a partir del clásico episodio de Diana y Acteón (Ovidio, Metamorfosis, III, 138-252), pues de hecho se trata de una dama arquera como la diosa y amenaza al cautivo hasta que este se disculpa por su atrevimiento.

Por su parte, La locura por la honra (ed. Florence d'Artois) introduce algunos ribetes de tragedia en un conjunto esencialmente ligero. Al comenzar el prefacio se reivindica la comedia como una piedra de toque para examinar un buen número de cuestiones (fronteras genéricas, historia y ficción, representación del poder, etc.) que laten en el centro de la crítica, pese a que ha sufrido el destierro del olvido. Tres son las fuentes principales que entreteje Lope, según d'Artois: el modelo de Ariosto, la gesta carolingia y la tradición romanceril, en concreto del romance de «La adúltera»-entre otros nombres- que proporciona el cañamazo para la comedia. El diálogo entre tragedia y tragicomedia, o el episodio transitorio de locura reciben merecida atención, pero 
especialmente agudo me parece la revisión del tratamiento de la figura real: según se aclara, Lope «se mueve según un criterio político interno a su dramaturgia y adaptado a ella, y que, según las necesidades de la acción, puede perfectamente imitar los principios de la política real como alejarse de ellos» (p. 189), guiado al mismo tiempo por el patrón genérico en cuestión. Del texto, bien fijado, se pueden cambiar algunas elecciones de puntuación: falta la segunda coma en v. 1244 («A Dios, conde, mi señor») y 1782-1783 («De Francia el delfín, / vuestro señor soy»), casan mejor unos puntos suspensivos al final de la amenaza del conde («[...] por dicha, si la viera...», v. 1745). Hay notas de gran finura (la retórica y el sentido del relato de catástrofe de vv. 2007-2014 o el viaje imaginario en busca de cordura que remite al Orlando furioso en vv. 2390-2426, por ejemplo), pero echo en falta comentar «los montes de la luna» (v. 889) en un parlamento poblado por Circe y Medea: se trata de un lugar tradicionalmente relacionado con la magia y los prodigios, que geográficamente se ha querido situar en África o Portugal, de donde sería el veneno más mortífero (por la conexión de la luna con la muerte), como se aprecia en otros loci lopescos (Arcadia, prosas y versos, ed. A. Sánchez Jiménez, Madrid, Cátedra, 2012, p. 301: «¿de qué Tesalia o monte de la luna / has cogido las hierbas de Medea?»). Y también «ajedrea» y «verbena» (v. 1004) entre las plantas del pasaje: mientras la segunda es una «[h]ierba conocida [...] por el mucho provecho y remedios que della se sacan o porque en los sacrificios usaban della» (Cov.), la primera es otra planta medicinal con diversas propiedades.

El mayordomo de la duquesa de Amalfi (ed. Teresa Ferrer Valls) es una de las calas más célebres de la comedia de secretario y de hecho más extremas, pues el enredo gira en torno a los amores secretos de Antonio con su señora y a los intentos por ocultar los hijos que tienen en común, más la catástrofe final. De las páginas prologales destacan los comentarios sobre el género palatino en su doble vertiente cómica y seria, la cara y la cruz de una misma moneda que representan respectivamente El perro del hortelano y El mayordomo. Ya en el tratamiento del texto, resulta acertada la enmienda del v. 243 («beldad»] «verdad», para evitar una reiteración léxica con el v. 240 y mejorar el sentido del pasaje). Quizás en las notas se podría apuntar un caso de antanaclasis («no tiene prenda que prenda», v. 544), una errata (en vv. 748-749 debe leerse «Secreto, Urbino, prometo, / (mas no prometo paciencia)», con conjunción adversativa y no adverbio comparativo) y una nueva propuesta de puntuación: una posible interrogación en vv. 1439-1442 («¿Ya qué tengo que saber, / a qué pruebas me apercibo...?»), en correlación con la pregunta que sigue (vv. 1443-1446).

Sigue El arenal de Sevilla (ed. Manuel Cornejo), una de las comedias hispalenses del Fénix. La estancia a orillas del Betis de Lope se detalla en la introducción, conjuntamente con una interesante propuesta de composición como un encargo relacionado con el conde de Niebla. La fijación del texto trae una buena enmienda para mejorar el sentido ("gantés» en lugar de «llantés», v. 32). En las notas hay interesantes precisiones sobre la lista de dramatis personae (en el elenco inicial), pero pueden perfilarse con algunos comentarios: «Alejandro Magno» como ejemplo de liberalidad (v. 127, explicado en otras comedias de la parte), la forma «her» por «hacer» (v. 225) es vulgar y no propia del estilo familiar, es preciso detallar la anécdota de Guzmán el Bueno a la que se alude en «la daga de Tarifa» (v. 491), señalar el juego entre «sol dado» y «soldado» (vv. 468 y 476); y notas nuevas: «fanales» (v. 505), «gallo» (v. 1348), «uñas» (v. 2344, como símbolo propio de ladrones muy cultivado por Quevedo) y «geomancía» (v. 2718, «Especie de magia y adivinación supersticiosa por los cuerpos terrestres, o con lineas, círculos o puntos hechos en la tierra», Aut.), amén de remitir al trabajo de L. 
Gómez Canseco («A otro perro con ese hueso. Antropofagia literaria en el Siglo de Oro», Etiópicas, 1, 2004-2005, pp. 1-32) para los «caribes» (v. 892). Muy dudoso me parece que el valentón Garrido sea un afeminado solo porque su nombre pueda valer «hermoso y lindo» (nota avv. 242-243), porque precisamente en este pequeño entremés empotrado en la comedia (vv. 237-280) se presenta como el típico bravo que suelta valentonadas y votos.

La historia de España resurge de nuevo en La fortuna merecida (ed. Ana Isabel Sánchez), con la privanza de Álvar Núñez de Osorio durante el reinado de Alfonso XI. El prólogo explica con solvencia los guiños directos al presente de Lope en la ficción, que parece enmarcarse en «una campaña propagandística» a favor del conde de Lemos durante los turbulentos años en torno al descenso de su aliado el duque de Lerma como «un intento de librar a su antiguo protector de la caída» (p.615). Igualmente estimables son las páginas dedicadas a las aportaciones lopescas al subgénero de la comedia de privanza y el lugar que merece en estas coordenadas La fortuna merecida (pp. 618-622). La edición madrileña de la parte es también aquí el texto escogido para la edición. De la anotación despunta la identificación del elenco de figuras dramáticas con personajes históricos y los tópicos amorosos que aparecen de verso a verso, más el tratamiento del monarca por parte de Lope (vv. 1083-1089, por ejemplo) y la explicación de un soneto moral de la primera jornada (vv. 136-149). Solamente falta explicar las «casa con malicia» (v. 168, conocidas asimismo como «casas a la malicia» porque disimulaban exteriormente sus verdaderas dimensiones) y la expresión «tomar los puntos» (v. 843, 'remendarse las roturas de las ropas con hilo de diferente color', pues no basta con remitir a la explicación de Don Quijote sin darla), indicar la condición de didascalia implícita del v. 1871 según revela el «cintarazo» (v. 1872) que menciona el criado Gonzalo y el sentido de «eternamente» como 'nunca' (v. 2559)

El bautismo del príncipe de Marruecos (ed. Gonzalo Pontón) comienza con la fallida expedición africana del rey de Portugal desde sus prolegómenos para centrarse en la recreación de la conversión al cristianismo del príncipe Muley Jeque, con la rivalidad por el trono del reino de Marruecos como telón de fondo. El estudio previo aclara bien el sustrato histórico, la fuente principal, las circunstancias, y fecha de redacción de la pieza. Precisamente, la revisión de ciertas señas internas permiten a Pontón reducir el marco de datación a 1602-1603 y así relacionar la comedia con un contexto histórico diferente que alumbra nuevas lecturas. El panorama textual (constituido por los impresos de la princeps más dos manuscritos derivados de ellos) no arroja apenas dificultades, pero Pontón hace gala de un estimable cuidado por los aspectos métricos y sugiere una prudente enmienda no documentada en la tradición («para aumentarte $e l$ dolor», v. 280, que solo comenta en nota). El profuso conjunto de referencias históricas reclama una anotación muy demorada, atenta tanto a las crónicas consultadas por Lope como a las innovaciones que realiza guiado por sus musas. Pues bien, el trabajo de Pontón es sin duda ejemplar en el rastro de relaciones y desviaciones en esta suerte de reescritura dramática. Con todo, una vez más, me atrevo a sugerir algunas aclaraciones más: tal vez «mercar» (v. 324) «sulcando» (forma etimológica de «surcar», v. 788), «agarrochado toro» (v. 1020, «toro herido» con «un género de dardos o varas que en su extremo tienen un harpón de hierro o acero» llamado «garrocha», Aut.) y «sollo» (v. 1825, «[p]escado conocido y de mucho precio», Cov., con más datos en Noydens) merezcan una breve nota oportuna, al igual que la petición poco clara «jasí Dios guarde a Quevedo!» (v. 1736), cuyo sentido no apuro. Más interesante es el v. 122: «el Sajón y el Francés preso» que dentro de un elogio al emperador Carlos $\mathrm{V}$ se refiere 
respectivamente a sus victorias sobre Juan Federico de Sajonia y Francisco I de Francia en las batallas de Mühlberg (1547) y Pavía (1525), a quienes mantuvo temporalmente encerrados hasta los acuerdos de Passau (1552) y Madrid (1526). La lista de erratas y la bibliografía cierran la Parte XI.

18 A pesar del celo mostrado en la búsqueda de precisiones de detalle, no difumina la claridad y solvencia del trabajo realizado. Una docena de comedias, en fin, que salen ahora pulcramente editadas y dispuestas para leerse y disfrutarse. Si pudiera verlo, Lope podría cesar de lanzar quejas por el estado en que circulaban sus comedias. En el día de hoy, el discreto lector puede disfrutarlas en condiciones óptimas.

\section{AUTORES}

ADRIÁN J. SÁEZ

CEA-Université de Neuchâtel 